\title{
Application of Neuroscience Principles for Evidence-based Design in Architectural Education
}

\author{
Andrea Rose McIntosh ${ }^{1 *} \&$ Nafisa M. Jadavji ${ }^{1}$
}

We spend approximately $90 \%$ of our time within a built environment, whether it is in our homes, offices, schools, city parks, or public spaces. This bears significance, as we are equally shaped by both our genetic makeup as well as our environment, which brings into question of how we experience space, and in turn how these experiences impact our behaviour. To gain a greater understanding of these impacts, neuroscience seeks to root out the principles of biological mechanisms involved in consciousness, spatial navigation and environmental stressors. However, the use of these principles is not discussed extensively within the curriculum of undergraduate or graduate architecture programs in North America. This paper aims to highlight that such information is critical to the advancement of evidence-based design by acknowledging the role of conscious awareness within space. An observable shift in the design community in collaborative neuroscience research can be seen in multi-sensory and virtual reality labs being constructed into design firms within North America. This review stipulates that architecture students should be prepared for the changes in quantifiable research and perceptual data collection coming to their field by examining the importance of neuroscience research in perception and consciousness. Architecture students who can interpret scientific research will not only have the advantage of a greater understanding of the human condition within space, but they will also be able to evolve the standard of design.

\section{INTRODUCTION}

Architects have long sought to inspire creativity, ingenuity, worship, community and awe using the tools at their disposal. Homo faber, "Man the Maker", crafts his environment, thereby controlling his fate. As a result of human ingenuity, we now spend over $90 \%$ of our time within a built environment crafted to suit our needs (Janda \& Janda, 2017). Design is inspired by societal reform and scientific exploration expressed as an art form in itself. If architecture is an expression of creativity as a mean to reflect on the human condition, one might argue that such a reflection can also be found within neuroscientific exploration of the mind. As we come to understand the biological mechanisms of perception, consciousness and their residual impacts on mental and physical health, there is question of how our environment might in turn affect those mechanisms.

Perception of space relies upon conscious awareness: the ability to receive and comprehend exterior and interior stimuli through

\footnotetext{
${ }^{1}$ Department of Neuroscience, Carleton University, 1125 Colonel By Dr, Ottawa, ON K1S 5B6

*To whom correspondence should be addressed: andreamcintosh@cmail.carleton.ca
}

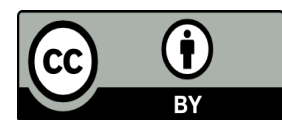

Except where otherwise noted, this work is licensed under https://creativecommons.org/licenses/by/4.0/

doi:10.22186/jyi.33.4.71-76 the use of the Global Workspace Theory. A good example of the interjection of neuroscience and architecture can be found in spatial navigation research. Scientific authors are capable of identifying floor patterns that are most and least useful to way-finding. Studies have also found that computer game and virtual reality architects may play an integral role in retaining memory and attention in elderly populations (Optale et al., 2010). Architectural students can benefit from a greater understanding of the impact of environmental stressors on biological mechanisms. Chronic stress response is one of the most pressing design problems as it may increase the risk of psychobiological disorders such as immune deficiencies, irritable bowel syndrome, depression, and anxiety (Hammen, 2015).

Neuroscience research permits an objective review of the usability and mental health impacts of space. "An informed architect could use this research as a means for evidence-based design (EBD), a concept which seeks to ratify design standards of the built environment by incorporating research from multiple disciplines into the design process." However, of the 113 post-secondary architecture institutions in North America, only the New School of San Diego offers students a certification program, which applies neuroscience principles to evidence-based practice ("Certificate in Neuroscience for Architecture" 2017). Although EBD is currently taught in many programs geared towards renewable/sustainable/green buildings, a truly multidisciplinary approach to EBD involves neuroscientific, psychological and economic research to guide design, a method commonly used in healthcare facilities today (Ulrich, Zimring, \& Zhu, 2008).

Students in architecture are entering a field which is now exploring ways to make use of neurobiological data analysis involv- 
ing environmental stimuli to achieve EBD. This review stipulates that architecture students will benefit from a greater understanding of conscious perception towards health-centric design. This will also allow them to collaborate with multisensory and virtual reality labs along with other cutting edge design firms and academic institutions merging neuroscience research into design.

\section{Neurological Influences of the Environment on Health}

Consciousness is perhaps the most important existential question that has yet to be solved. It is described in a number of ways in relation to philosophical, psychological, and neuroscientific interpretation. It is broadly defined as "the mind", the perceptual awareness of external and internal stimuli, which influence cognitive activity (Searle, 2000). Consciousness is often considered separate from other neurological mechanisms that humans share due to its qualitative and subjective nature. The majority of consciousness research has been conducted on the verbal and behavioural assessment of participants. These findings can be questionable as we all experience our environment, our personalities, and our memories differently thereby increasing the chance of error in experimental findings. However, consciousness is an entirely biological phenomenon and subjective ontology challenges, but does not prevent an objective scientific research. The breadth of this field touches upon multisensory interpretation, memory recall, attention and various cognitive mechanisms; however, this section will focus on the conscious effects of our environment on wayfinding and stress.

Through the use of electroencephalography (EEG) and functional magnetic resonance imaging (fMRI), neuroscientists attempt to identify the neuronal pathways, which produce the conscious experience. The Global Workspace Theory (GWT) is widely accepted in the scientific community to be representative of conscious and unconscious processes (Prakash et al., 2008). It is similar to the concept of working memory in that GWT proposes experience to be momentary and subjective. Multisensory stimuli (conscious) are initially interpreted by various cognitive processes (unconscious), which is referred to as the "receiving process". This information can then be used to produce a movement, emotion, or behaviour. GWT lends itself quite readily to computational modeling and can distinguish the brain regions impacted by competition of sensory modalities (e.g., a video and its audio being out of sync).

\section{Way-Finding and Spatial Awareness}

There are a multitude of research initiatives involving the brain and behaviour within the environment. Way-finding will be used as a practical example to showcase the power of design as a psychobiological influencer on behaviour and health. Way-finding is the neurophysiological experience of self while navigating the environment. This biological mechanism allows us to locate ourselves within space by taking in information from visual and auditory cues while simultaneously utilizing stored spatial memories. The environmental cues paired with spatial memory then allow for a decision to be made via limb movement and body axis direction
(Macagno, 2014). Way-finding is a particularly relevant tool in design as spatial alignment efficiency can either aid navigation or cause confusion and unease within the built environment.

Way-finding can be categorized by the activation of neuronal pathways that create a cognitive mapping system. Nobel Prize laureate John O'Keefe and Lynn Nadel researched hippocampal cell signalling in rats. They found that specific groups of neurons, termed "place cells", fired when rats either tasked with location recall or object recall (O'Keefe \& Nadel, 1978). The authors stipulated that place representations within the hippocampus were activated together depending on the physical and perceived distances between places. Later on these findings formed the basis of the theory of "grid cells", place-modulated cells in the presubiculum and hippocampus which fire in a crystal-like fashion in conjunction with head-direction neurons (Boccara et al., 2010). The discovery of hippocampal involvement of place cells and grid cells has offered a fascinating insight on the way we understand geometric boundaries, spatial memory and directional movement. These findings may be especially significant to architects when considering the effects of floor misalignment on the perception of our environment. Designers may also take advantage of research involving the deterioration of the aging hippocampus which impacts spatial memory in the geriatric population.

One of the ways that a building is considered a success is in the functional ease of navigation. There is a positive correlation between the perceived figural complexity of space and how the actual space reflects that perception (Weisman, 1981). If misaligned, the spatial structure of the built environment can be known to cause cognitive dissonance with way-finding. A study performed in 2004 by Werner and Schindler studied this effect via the use of a computer program simulating various aligned, misaligned, connected and disconnected floor plans (Figure 1). Fifty-six participants familiarized themselves with a digital interface and an assigned floor plan. They were then instructed to find five target objects within the span of five minutes (Werner \& Schindler, 2004). The authors found that misalignment to a central reference frame reduced the speed of accuracy in finding objects by $25 \%$ as compared to aligned floor plans. When participants were asked to point in the direction they believed an object might be according to a specific floor plan their pointing error was on average greater for misaligned than aligned floor plans (Werner \& Schindler, 2004). These findings represent an exciting example of how neuroscience can interject itself into architectural education. The orientation of a floor plan can directly impact the usability and positive experience within space, this information can help disseminate patterns of design that are more efficient, thereby reducing spatial dissonance.

Finding our position within space is directly impacted by our ability to recall the layout and landmarks of our environment, and this ability deteriorates significantly with age. From approximately 50 years onwards, MRI scans reveal a decline in white matter volume, reaching up to $26 \%$ in reduction at 90 years old (Gunning-Dixon, Brickman, Cheng, \& Alexopoulos, 2009). This 


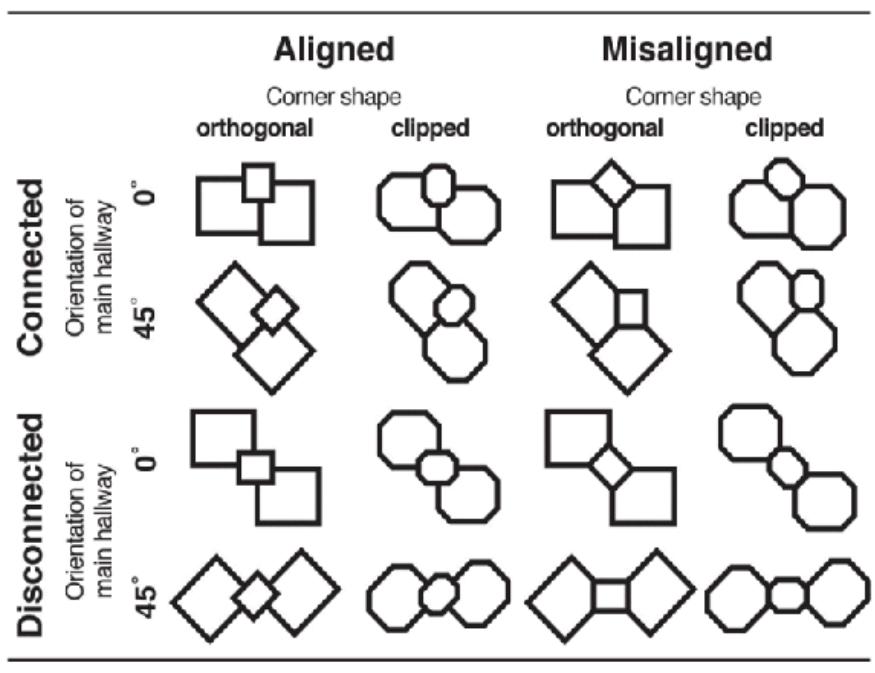

Figure 1. 16 floor plans, the top two rows are connected (at $0^{\circ}$ and $45^{\circ}$ ), the two rows at the bottom are disconnected floor plans (at $0^{\circ}$ and $45^{\circ}$ ) (Werner \& Schindler, 2004). Findings suggest that aligned floorplans reduce effort to establish spatial navigation.

cell loss is detrimental to hippocampal functioning, the principle region responsible for spatial memory in regards to navigation and orientation. However, research suggests that enriched environments have positive neurological benefits for the geriatric community. Researchers took a novel approach of using virtual reality (VR) to determine the possible effects on cognition and memory (Optale et al., 2010). The participants, a median age of 80 years old, were placed in either a VR memory training experimental group or control group for 6 months. The VR training involved simulated visuo-auditory environments and focused on way-finding scenes. The authors found that participants treated with VR memory training had better long term memory and cognitive functioning than the control group which they theorized may have been caused by a boost in attention capabilities. Way-finding and memory training using virtual reality environments designed using perception based learning programs can be used to reinvigorate spatial memory recall.

How we design our built environment influences the ways that we behave within that environment. There should be an educational focus on tested principles in way-finding to promote evidencebased design. Using research, we can disseminate the floor plans that generate the greatest positive response to navigation within space. When considering aging populations architects can assist virtual reality programmers in creating enriched environments that can improve spatial memory.

\section{Impact of Environmental Stressors on Health}

The stressors within our environment can shape our health. This is particularly true of how chronic stress can cause immune deficiencies and increase susceptibility to psychobiological disorders. The hypothalamic-pituitary-adrenal (HPA) axis is the pathway which mediates stress response. As a survival tactic, HPA axis activation causes physiological changes such as disruption of the digestive system, vasodilation and the release of adrenaline. The HPA axis secretes glucocorticoid cortisol, an anti-inflammatory response hormone, to suppress inflammatory cytokine production. This can be accomplished by inhibiting pro-inflammatory gene promoters, blocking in cell cascades effects, and antagonizing protein-protein interactions which mediate cytokine production (Slavich \& Irwin, 2014). Under chronic stress circumstances we can observe a glucocorticoid resistance, as immune cells become less sensitive to anti-inflammatory mechanisms, causing an inability to properly regulate rising cytokine levels (Schleimer, 1993). Inflammation also causes an up regulation of enteroendocrine cells which produce serotonin, permeating the sympathetic response of the HPA axis (Spiller et al., 2000). Therefore, chronic stress can cause immune response irregularities, which can in turn increase susceptibility to common viral attacks and functional disorders, and diminish our capacity to mitigate future stress responses.

The immune system is the body's first line of defense against viral, pathogenic and bacterial infections. This is accomplished by first detecting the agent, and then sending neural and endocrine signals to the brain. These signals up regulate the creation of inflammatory response cytokines IL-6, IL-1, and TNF- $\alpha$ to the affected area in an effort to contain the infection (Slavich \& Irwin, 2014). Genetic predispositions towards inflammation and stress response inhibition combined with the impact of environmental stressors have been connected to an increased risk to functional disorders such as irritable bowel syndrome (IBS) (Drossman, Camilleri, Mayer, \& Whitehead, 2002). It is estimated that approximately $10-25 \%$ of the population is affected at some point but only $30 \%$ of those suffering from IBS are likely to seek out treatment (Drossman et al., 2002). Overexposure of proinflammatory cytokines and cortisol may also increase susceptibility to heightened states of anxiety and depression. Furthermore, deregulation of the HPA axis can impact synaptic plasticity as well as dopaminergic and serotonin output within the striatal areas, the amygdala, and the hippocampus (Hammen, 2015).

Furthermore, maladaptive stress response can be transmitted through transgenerational epigenetic modification. In rodent and primate models, we can observe prevalence in genetic expression instigated by stress response across multiple generations (Franklin et al., 2010). Studies have shown that unpredictable home environments in rats can reduce 5HT1A receptor expression in the dorsal raphe nucleus in descendants (Franklin et al., 2010). This change in receptor expression is akin to the pathogenesis seen in antisocial behaviours and personality disorders (Gudsnuk \& Champagne, 2012). Vulnerability to stress induced psychobiological disorders is perhaps the most urgent health contingency that neuroscience research can address in the greater development of evidence-based design architecture.

\section{EVIDENCE-BASED DESIGN}

Evidence-based design (EBD) involves the use of clinical research in the design concept of the built environment to improve health, 
productivity, and economic outcomes. It is a relatively new approach as it prioritizes objective and quantifiable results. EBD utilizes mounting research from neuroscience, environmental psychology, architecture, and behavioural economics to produce a framework of desired outcomes from our buildings. This section will review the process of EBD in addition to the architecture curriculums integrating of neuroscience and architecture. Furthermore, there will be an observation of the benefit of EBD in the design of health care facilities.

\section{EBD and Neuroscience}

There are a multitude of comparisons in the way science and design curriculums measure feasibility of findings and outcomes. Scientific concepts must be grounded within specific methods intrinsic to their validity. Publication of findings is critical to the advancement of research as it allows for objective review. The architectural approach differs as the interpretation of design is often subjective when considering the cultural and artistic ramifications of a structural landmark. Design is often led by trend or form, a novel build is often praised for its avant-garde design and emphasis on function can be perceived as a detriment to creativity. However, neuroscience research involving perceptual stimuli and its impacts on behaviour and health can be used to improve the current practice. As in scientific exploration, architecture may see its greatest advancements once design research is integral from building conception to measured impact and publication of findings.

A truly progressive curriculum expands onto scientific dialogue, which seeks to validate how to best enhance the human experience and eliminate the designs that are not beneficial. Students must understand the components which are conducive to those human experiences in order to conduct an evidence-based practice of responsible design. One post-secondary curriculum which stands out amongst others in terms of neuroscience and architecture integration is the New School of Architecture in San Diego. This is the first educational institution in the world to offer a certificate program in Neuroscience for Architecture ("Certificate in Neuroscience for Architecture" 2017). The courses focus on four areas that involve evidence based design practice. Students learn about environmental psychology, which is the quantifiable relationship between environment and behaviour. There is also an overview of the neurological components responsible for sensory and cognitive responses, which permit human experience within space. Students have access to neuroscience seminars focus on how to best improve health care facilities, educational, spiritual, and corporate environments using neuroscience principles. The integration of these concepts is further solidified with studio time geared towards applying these principles towards the built environment.

This program was developed by fellow of AIA and founder of the Academy of Neuroscience for Architecture (ANFA) John Eberhard, along with Dr. Eve Edelstein, $\mathrm{PhD}$ in Neuroscience and MA in Architecture. Both have extensive backgrounds in research and practical application of neuroscience within the built environment. Eberhard is the author of such behavioural neuroscience and architecture books such as "Inquiry by Design"(with John Zeisel, 2006), "Architecture and the Brain" (2007), and "Brain Landscape" (2008). His involvement in promoting neuroscience based EBD led to the creation of ANFA, a nexus of both fields in collaboration and research. Dr. Edelstein is the world's first PhD Neuroscientist with a master in Architecture. She has contributed to over 43 scientific papers involving the impact of the environment on the body and brain. As a faculty member of the New School, Dr. Edelstein is educating architecture students on the concept of the built environment as a psychobiological influencer on behaviour and health. She is also the founder of Innovative Design Science, which is a design firm that specializes in implementing neuroscience research, virtual reality mock-ups, on-site design studies, as well as pre- and post-occupancy evaluations of the build. Students in San Diego are privileged to take part in a new approach towards architectural education, as they will come to understand the benefits of neuroscience and EBD in creating better buildings for its occupants.

\section{The Role of EBD in Healthcare}

EBD is most commonly used in the design of healthcare facilities. This may be due to the higher risks associated with hospitals which demand informed design to minimize loss. The concept of EBD first emerged in the 1960s as American and British health care providers measured the impact of spatial alignment and wayfinding of floor layouts on staff productivity (Clipson \& Johnson, 1987). Today, its method has been widely adopted by health care providers across North America. Notably, the US military Health System has constructed over 70 hospitals totalling \$6 billion dollars in construction (Ulrich, Zimring, \& Zhu, 2008). EBD in healthcare focuses primarily on four components: mental health improvement for patients and staff, patient recovery, staff productivity, and the use of evidence-based metrics.

The Center for Health and Design has provided a universal list of guidelines to perform EBD in healthcare facilities. The first step involves a literature review of neurological, psychological, architectural and economic research in relation to the problems the project is attempting to solve. Financial operations also need to be considered in association to multi-year investment returns and cost-effectiveness of design options. SWOT analysis is used as a decision-making tool in the placement of technical and safety healthcare features. Furthermore, the design team is heavily involved with patients and staff in regards to surveys, simulations, and pre- and post-occupancy evaluations. The goal of this method is to acquire as much information as possible in regards to healing environments to guide the construction of the facility.

The impact of EBD in healthcare is that of a measureable improvement in health outcomes, which leads to a reduced chance of infection and medical error, thereby reducing the length and cost of a patient's stay. Researchers performed a meta-analysis of healthcare facility layouts and patient recovery time (Ulrich et al., 2008). The findings suggested that single patient rooms reduced the chance of infection, allowed for better communication 
with staff, and length of stay (Ulrich et al., 2008). The Agency for Healthcare Research and Quality (AHRQ) is currently leading the way in EBD by lobbying for the health and economic research in hospital design. The center advocated the use of EBD as a means to reduce avoidable incidences by using single patient room layouts, acuity-adaptable rooms and accessible nursing stations (Shoemaker \& Kazley, 2010). The AHRQ also mentioned that too often there are no clear, measurable or expected outcomes for large design projects. Although EBD demonstrates these features readily, it is not widely adopted throughout the field of design (Shoemaker \& Kazley, 2010). These concepts are beneficial to more than just the healthcare community as the use of EBD can transfer over to all building types and occupancy groups to improve living standards.

An understanding of scientific analysis impacts the ability for designers to implement the important research of perceptual awareness, behavioral interaction and consciousness into the conception of various structures. Educating architecture students in neuroscience allows for an EBD approach to be implemented in all areas of design. If students are more experienced with research and foster a greater awareness of the use of measurable impacts on health, they will be equipped with the knowledge to push design standards forward.

\section{CONCLUSION}

The future of architectural design will depend upon the advancement of evidence-based design and the inclusion neuroscientific research regarding the human experience within space. Studies involving consciousness and the Global Workplace Theory can be used to teach design students about neural correlates which permit conscious awareness (Mallgrave, 2010). A fitting example of neuroscience in architecture is found in the research involving spatial navigation and way-finding. The alignment of floor plans and their feasibility can be monitored and designed to permit the greatest ease in locating one's self within a build environment. The aging population may also be presented with virtual reality experiences designed by computer game architects to improve memory and attention capacity (Optale et al., 2010). Neuroscience research may also be used to study the effect of environmental stressors on mental health. Students, receiving an overview of chronic HPA axis activation and its role in psychobiological disorders such as IBS, depression, anxiety and transgenerational modifications, have a responsibility to minimize the impact of stress in our daily lives through responsible design. Should students be more aware of the influence of design on the health mechanisms that allow conscious interpretation to take place, they would be more capable to participate in evidence-based design practices.

There is only one architectural program in North America which offers a Certificate in Neuroscience for Architecture; it is offered at the New School of San Diego. Students come into contact with the benefits of EBD with courses on environment and behavior, an overview of the conscious response within space, neuroscience seminars, as well as studio time dedicated to the merger of both disciplines ("Certificate in Neuroscience for Architecture" 2017). EBD is currently taught in many Architectural programs, but the course work only relates to the use of energy efficiency research to increase sustainability rather than neurobiological research to enhance perceptual experience. However, the application of neuroscience principles in EBD is widely accepted in one area of architecture today, healthcare facilities. The multidisciplinary approach involves extensive background research, patient and staff health, and economic feasibility by implementing design standards that will reduce the length and cost of a patient's stay. The methods used in the design of healthcare facilities and their measurable outcomes can be applied to any building type. Designers working specifically within EBD using neuroscience research demonstrate that the methods can be taught in architectural programs to promote responsible design.

The limitations of the present research involve the subjective nature of the conscious experience. The greatest challenge to the application of neuroscience as a tool in EBD involves its acceptance within the architectural community. Neuroscience and EBD are generally found within healthcare design as the planning, financial, and life risk implications are extensive. The design process is much greater and more time consuming than other builds on average. However, students stand to benefit from scientific incorporation within design, if only to have a better understanding of the impact of their work.

The future directions of the merger of these two fields involve the use of interactive labs funded by governmental agencies and architecture firms in collaboration with academic institutions. Public access to design research will improve social welfare by eliminating the design standards that are not conducive to occupant health and wellbeing. Architecture firms will need to look at the impact of their builds and become accountable for their health impacts. This may be accomplished by performing post-hoc analyses, animal and human lab research, retrieving foot traffic sensor data, satisfaction surveys and virtual reality prototyping. Before, we could look at architecture as a balance between form and function, which mostly based on what we feel rather than what we can prove as the science was not present. Allowing design to go on without accountable measures of perceptual adaptation when they are now becoming available through research negates advancement within the field and students should be ready for the changes to come in their profession.

\section{REFERENCES}

Askenasy, J., Lehmann, J., \& Voss, U. (2013). Consciousness, Brain, Neuroplasticity. Frontiers in Psychology, 4, 1-10. doi:10.3389/fpsyg.2013.00412

Boccara, C. N., Sargolini, F., Thoresen, V. H., Solstad, T., Witter, M. P., Moser, E. I., \& Moser, M. (2010). Grid Cells in Pre and Parasubiculum. Nature Publishing Group, 13(8), 987-994. doi:10.1038/nn.2602

Certificate in Neuroscience for Architecture. (2017). Retrieved from http://newschoolarch.edu/academics/professional-development/certificate-in-neuroscience-for-architecture/

Clipson, C., \& Johnson, R. (1987). Integrated Approaches to Facilities Planning and Assessment. Planning for Higher Education, 15(3), 12-22. 
Drossman, D. A., Camilleri, M., Mayer, E. A., \& Whitehead, W. E. (2002). AGA technical review on irritable bowel syndrome. Gastroenterology, 123(6), 2108-2131. doi:10.1053/gast.2002.37095

Franklin, T. B., Russig, H., Weiss, I. C., Gräff, J., Linder, N., Michalon, A., ... Mansuy, I. M. (2010). Epigenetic Transmission of the Impact of Early Stress Across Generations. Biological Psychiatry, 68(5), 408-415. doi:10.1016/j. biopsych.2010.05.036

Gudsnuk, K., \& Champagne, F. A. (2012). Epigenetic Influence of Stress and the Social Environment. Ilar Journal, 53(3), 279-288.

Gunning-Dixon, F., Brickman, A., Cheng, J., \& Alexopoulos, G. (2009). Aging of Cerebral White Matter: A Review of MRI Findings. Journal of Geriatric Psychiatry, 24(2), 109-117. doi:10.1002/gps.2087.Aging

Hammen, C. L. (2015). Stress and Depression : Old Questions , New Approaches. Current Opinion in Psychology, 4, 80-85. doi:10.1016/j.copsyc.2014.12.024

Janda, K. B., \& Janda, K. B. (2017). Buildings don't Use Energy: People do. Architectural Science Review, 54(1), 15-22. doi:10.3763/asre.2009.0050

Macagno, E. (2014). Direct relevance of the 2014 Nobel Prize in Physiology and Medicine to Neuroscience and Architecture, and to the mission of ANFA (pp. 1-3). La Jolla, CA: ANFA.

Mallgrave, H. F. (2010). The Architect's Brain. Est Sussex, UK: John Wiley \& Sons Ltd.

O'Keefe, J., \& Nadel, L. (1978). The Hippocampus as a Cognitive Map. Oxford Clarendon Press.

Optale, G., Urgesi, C., Busato, V., Marin, S., Piron, L., Priftis, K., ... Bordin, A. (2010). Controlling Memory Impairment in Elderly Adults Using Virtual Reality Memory Training : A Randomized Controlled Pilot Study. Neurorehabilitation and Neural Repair, 24(4), 348-357. doi: 10.1177/1545968309353328

Prakash, R., Prakash, O., Prakash, S., Abhishek, P., \& Gandotra, S. (2008). Global Workspace Model of Consciousness and its Electromagnetic Correlates. Annals of Indian Academy of Neurology, 11(3), 146.

Schleimer, R. P. (1993). An overview of glucocorticoid anti-inflammatory actions. European Journal of Clinical Pharmacology, 45(1 Supplement), 3-7. doi:10.1007/BF01844196

Searle, J. R. (2000). CONSCIOUSNESS. Annual Review Neuroscience, 23, $557-$ 578.

Shoemaker, L. K., \& Kazley, A. S. (2010). Making the Case for Evidence-Based Design in Healthcare : A Descriptive Case Study of Organizational Decision Making. HERD, 4(1), 56-88.

Slavich, G. M., \& Irwin, M. R. (2014). Social Signal Transduction Theory of Depression, 140(3), 774-815. doi:10.1037/a0035302.From

Spiller, R., Jenkins, D., Thornley, J., Hebden, J., Wright, T., Skinner, M., \& KR, N. (2000). Increased Rectal Mucosal Enteroendocrine Cells, T Lymphocytes, and Increased Gut Permeability Following Acute Campylobacter Enteritis and in Post-Dysenteric Irritable Bowel Syndrome. Gut, 47(6), 804-11.

Ulrich, R. S., Zimring, C., \& Zhu, X. (2008). A Review of the Research Literature on Evidence-Based Healthcare Design. Sage Journals, 1(3).

Weisman, J. (1981). Evaluating Architectural Legibility:Way-Finding in the Built Environment. Environment and Behavior, 13, 189-204.

Werner, S., \& Schindler, L. E. (2004). Frames in Architecture: Misalignment Impairs Way-Finding Performance. Environment and Behavior, 36(4), 461-482. doi: $10.1177 / 0013916503254829$ 